\title{
UNA MIRADA A LOS REQUISITOS DE LA OBTENCIÓN DE LA NACIONALIDAD ESPAÑOLA POR RESIDENCIA
}

\author{
A GLANCE AT THE REQUIREMENTS FOR OBTAINING THE \\ SPANISH NATIONALITY BY RESIDENCE
}

\author{
María Elena Cobas Cobiella \\ Universidad de Valencia. España/Spain \\ m.elena.cobas@uv.es
}

Recibido/Received: 11/08/2014

Aceptado/Accepted: 23/09/2014

\section{RESUMEN}

Vivimos en un mundo globalizado y la movilidad de las personas es identificativo de la modernidad, por esta razón la obtención de la nacionalidad española por residencia constituye un tema de importancia en el entorno social, económico, político y jurídico español. Para un extranjero adquirir la nacionalidad es un largo camino transitado más de espinas que de rosas, por ello este tema requiere ser visto con toda la seriedad que sea posible. El objetivo de este trabajo es reseñar algunas de las doctrinas de la jurisprudencia más actualizada en la materia, en relación a los requisitos exigidos para la obtención de la nacionalidad española. Partiendo de la premisa, que cuando un extranjero llega a adquirir la misma, es como llegar a la tierra prometida, "al Dorado".

\section{PALABRAS CLAVE}

Nacionalidad, autorización para residir y trabajar, extranjero.

\section{SUMARIO}

1. Presentando la cuestión. 2. Algunas notas preliminares sobre la nacionalidad. 3. Los requisitos para la obtención de la nacionalidad. 4. Concluyendo el tema. Bibliografía

\begin{abstract}
We live in a globalized world and the mobility of people identifies the modernity of our time. Therefore, obtaining Spanish nationality by residence is an important issue in the Spanish social, economic, political and legal environment. For a foreign to acquire the nationality is a long road to travel with more thorns than roses, so this issue needs to be seen as seriously as possible. The objective of this work is to outline some of the doctrines of the latest case law on the subject, in relation to the requirements for obtaining Spanish nationality. Starting from the premise that when a foreigner comes to acquiring the nationality, it is how to get to the promised land, "El Dorado".
\end{abstract}

\section{KEYWORDS}

Nationality, authorization of residence and work, foreign.

\section{CONTENTS}

I. Introducing the topic. 2. Some preliminary notes on the nationality. 3. Requirements for obtaining citizenship. 4. Concluding the topic. References 


\author{
Un caballero alegre y audaz \\ de día y de noche cabalgando va. \\ $Y$ canta su canción mientras sigue osado \\ a la busca de El Dorado. \\ Pero vano fue su esmero \\ y ya viejo el caballero, \\ por la sombra el corazón sintió apresado, \\ al pensar que nunca el día llegaría \\ en que hallaría El Dorado.
}

Edgar Allan Poe

\section{PRESENTANDO LA CUESTIÓN}

Vivimos en un mundo globalizado, y Europa, y dentro de ella España, se ha convertido en la última década en un centro importante de movilidad humana y de circulación de personas, en busca de un mundo mejor, y aunque en estos momentos el proceso por una parte se ha ralentizado en determinados sectores, por la crisis económica, y por las dificultades de acceder al mercado de trabajo, diariamente siguen siendo foco de atención las noticias relacionadas con la inmigración y con la llegada de inmigrantes ilegales a España, a la par que muchos españoles comienzan a emigrar hacia otras latitudes en busca de trabajo y de dignidad como personas y muchos extranjeros que había venido a España en busca de un futuro, han regresado a sus países de origen.

Este entorno hace que la nacionalidad y todas las cuestiones en relación a ella, vuelvan a estar en el punto de atención de los estudiosos del tema, a lo que se unen recientes reformas legislativas que se otean en el horizonte, que indican que en 2015 o 2016, la gestión del Registro Civil pasará a manos de los Registradores Mercantiles, aunque según plantea el Ministerio de Justicia en voz de su Ministro Alberto Ruiz Gallardón, la titularidad del mismo seguirá siendo pública y la gestión gratuita. Con el tiempo se irá desbrozando el camino.

El masivo proceso de regularización de extranjeros en 2005 trajo como consecuencia que en 5 años o más, muchos de aquellos extranjeros- contando con la hipotética idea- de que siguieran trabajando y contando de que tuvieran los requisitos que la ley de extranjería regula para acceder a las autorizaciones de residencia para vivir y trabajar, estuvieran dentro del grupo de personas con derecho a acceder a la nacionalidad española.

A pesar de ello, debo decir que la nacionalidad no ha sido una prioridad para el Estado, por ello a principios del año 2012 el número de expedientes en los que se solicitaba la nacionalidad española por residencia acogiéndose a lo previsto en los artículos 21 a 23 y 27 Código Civil, 220-224 Reglamento del Registro Civil, Ley Orgánica de Derechos y Libertades de los Extranjeros en España y su integración social de 11 de enero de 2000 alcanzaba un número bastante elevado que ascendía a los 400.000 sin olvidar que cada mes esa cifra se incrementaba en 10.000 nuevos expedientes y la obtención de la nacionalidad podía tardar entre dos y hasta seis años.

Con la suscripción por parte del Ministerio de Justicia con el Colegio de Registradores de la Propiedad y Mercantiles de España de un Convenio en fecha 25 de junio de 2012, denominado Encomienda de gestión para que los Registros de la Propiedad y Mercantiles prestasen su apoyo técnico en la tramitación de dichos expedientes que habían tenido entrada en la Dirección General de los Registros y del Notariado entre los años 2010 y 2012. Ello 
suponía el nacimiento del Plan Intensivo de Tramitación de Expedientes de Adquisición de la Nacionalidad Española por residencia, que fue asumido como ya se ha dicho por el Colegio de Registradores. Posteriormente el 19 de abril de 2013 se firmó una nueva encomienda para continuar los trabajos realizados, y que prevé la tramitación por los Registradores de los expedientes de nacionalidad por residencia, con entrada en el Centro de Digitalización del Colegio a fecha 31 de diciembre de 2013 (Navarro, et al. 2013:8-9).

$\mathrm{Y}$ así nos encontramos de nuevo con una puesta en escena de los requisitos para obtener la nacionalidad española por residencia y trabajo contemplados en el Código Civil español, los que en este trabajo retomo pero con la óptica de la jurisprudencia; decisión que no es frívola, al contrario ha sido pensada y meditada, interesa siempre a los extranjeros saber cómo piensan nuestros tribunales en relación a los requisitos que se necesitan para poder optar por la nacionalidad española.

\section{ALGUNAS NOTAS PRELIMINARES SOBRE LA NACIONALIDAD}

\section{a) Nacionalidad. Estado de la cuestión}

La nacionalidad reviste una gran significación para el Derecho cuestión que no debe pasar inadvertida, a efectos de cualquier trabajo que se ocupe de ella. Constituye a la par de un derecho fundamental un estado civil, que incide directamente en la capacidad de obrar de las personas, les acompaña desde su nacimiento y afecta sus leyes más personales, ya que constituye la ley nacional que regula la capacidad de sus ciudadanos en cualquier parte del mundo donde se encuentren y en su propio país, a lo que se une la connotación política por su carácter constitucional, aunque sea el Código Civil el que le regule jurídicamente (Cobas Cobiella, 2013:2).

La importancia de la nacionalidad trasciende el marco político, de la pertenencia a un Estado determinado, desde el punto de vista práctico significa el final para los extranjeros de un largo camino recorrido desde que se llega a España, hasta la obtención de la misma y no precisamente un camino plagado de rosas", más bien de espinas, me atrevo a decir, desde mi experiencia personal.

La observación de especialistas en la materia resulta interesante y polémica a la vez, (Ortega et al. 2013) cuando advierten que "por tanto, eso sí, la nacionalidad (española, en nuestro caso) bien vale un precio. Debe merecerse y debe suponer un cierto esfuerzo en lo que respecta a la asimilación de la historia, de la cultura y de la lengua de la sociedad de acogida. Querer venderla barata o casi regalarla es totalmente irresponsable y peligroso". Efectivamente hay cuestiones básicas que un extranjero debe dominar para poder acceder a la nacionalidad (idioma, costumbres, etc.), obviar esto sería una irresponsabilidad, pero si cabe señalar que la trayectoria para poder obtener la nacionalidad es larga y dura, empezando por los plazos (que como veremos posteriormente pueden ir desde dos hasta diez años de la vida de una persona), los documentos que hay que aportar y los requisitos que hay que tener, de ahí que cuando una persona llega a esa etapa, para nada obtiene un regalo, cuesta mucho llegar al momento en que el organismo facultado, dé por válida toda la documentación y conceda la nacionalidad.

A lo que se une la falta de uniformidad y coherencia que ha matizado la actuación de los Registros Civiles en esta materia, que resumiendo podemos calificar de autónoma y anárquica, cuestión que puede ser consecuencia de la regulación general del Código Civil español en sus artículo 21 y 22. En este sentido debemos recordar que al promulgarse el 
Código Civil en 1888, España era un país de emigrantes, los españoles emigraban a hacer Las Américas; no era una norma preparada para recibir inmigrantes. Texto que ha permanecido inamovible a lo largo del tiempo. Eso sí, acompañado por algunas Instrucciones bastante recientes que han intentado ofrecer uniformidad a la cuestión, así tenemos la Instrucción de 26 de julio de 2007 de la Dirección General de los Registros y el Notariado, sobre tramitación de las solicitudes de adquisición de la nacionalidad española por residencia ( BOE número 189, de 8 de agosto de 2007), cuya finalidad fue la de mejorar y unificar la conformación del expediente de adquisición de la nacionalidad por residencia, velando además por el derecho de los menores cuando sean los interesados en el procedimiento, presidido por el principio de estabilidad. Además en la citada Instrucción se potencia el papel de la fiscalía como guardián de la legalidad y del control de la instrucción del expediente y que tuvo dos puntos claves, la supresión de la aportación por el interesado del certificado de residencia y antecedentes penales y de la documentación referida a la residencia en España.

Posteriormente, en 2012 se aprobó la Instrucción de 2 de octubre de 2012, de la Dirección General de los Registros y del Notariado, sobre determinados aspectos del plan intensivo de tramitación de los expedientes de adquisición de la nacionalidad española por residencia (BOE, número 247 de 13 de octubre de 2012), con la finalidad esencial de agilizar los procedimientos de concesión de nacionalidad por residencia, que a pesar de sus detractores, como ya he afirmado en otro ocasión, ha tenido dos finalidades importantes, la primera proteger a los más desvalidos, y la segunda ofrecer agilidad y uniformidad a la concesión de la nacionalidad (Cobas, 2013:15).

La obtención de la nacionalidad es importante, ya que permite a la persona ostentar determinados derechos por su pertenencia a un determinado país y como contrapartida a su vez obliga a la persona a cumplir con la misma, y con una especial incidencia en su estatuto jurídico. Esta importancia abarca lo laboral, lo social, lo económico y lo jurídico, y habilita a la persona para el ejercicio de determinados derechos, tal como ha referido la jurisprudencia en la materia cuando desarrolla todo el plus que le concede a una persona la nacionalidad de un país determinado, así recrea entre los derechos que se ostentan "el derecho a participar en los asuntos públicos, directamente o por medio de representantes, libremente elegidos en elecciones periódicas por sufragio universal, y a acceder en condiciones de igualdad a las funciones y cargos públicos", Vid. Sentencia del Tribunal Supremo, Sala de lo ContenciosoAdministrativo (Sección 6ta), de 26 julio de 2004, (RJ\2004\5546). Nótese además, como se argumenta en esta sentencia, que el acto de conferir la nacionalidad no constituye un simple acto administrativo, porque requiere una acusadísima cualificación, que le hace singular frente al resto de actos administrativos, ya que ni siquiera una Ley o un Tratado "puede hacer lo que mediante ese acto, previa la cuidadosa y prudente apreciación de la concurrencia de los requisitos que la Ley establece, puede hacerse", según la citada sentencia.

Por esta razón, al resolver un determinado asunto, en que un ciudadano libanés y casado con española, solicitó la nacionalidad española, el Tribunal consideró absurda la tesis planteada de que la mala conducta habitual, y la pertenencia a una organización criminal (tráfico de drogas) se borra, con un año de permanencia legal en España, teniendo una buena conducta, por lo que le fue denegada la solicitud de nacionalidad española. Porque tal como se ha referido en la Sentencia del Tribunal Supremo de 16 de marzo de 1999, Sala de lo Contencioso-Administrativo, Sección 6a , (RJ\1999\3044), es necesario distinguir el supuesto de concesión de nacionalidad de aquellos otros en que se solicite el reconocimiento de un derecho subjetivo, ya que la concesión de nacionalidad es un estado de manifestación de la soberanía de un Estado, ya que el supuesto a que se refiere el artículo 22 del Código Civil, la concesión de nacionalidad, es harto distinto del mero reconocimiento de un derecho, lo que 
dignifica la idea de la importancia de la nacionalidad, tal como ratifica la Sentencia del Tribunal Supremo de 22 de diciembre de 2003 (RJ/2004/764) al decir "cualidad que lleva implícita un conjunto de derechos y obligaciones, condicionado al cumplimiento de los requisitos de la ley".

\section{b) Nacionalidad como estado civil}

La singularidad de este acto administrativo hace que me incline por apreciar la nacionalidad como un estado civil, en concordancia con el planteamiento de la mayoritaria doctrina jurisprudencial en la materia, en primer lugar porque tiene una doble dimensión pública y privada, la primera porque forma parte de la organización estatal, y de una cualidad que caracteriza a los que pertenecen a una determinada comunidad, esa es su arista pública, mientras que la privada es porque afecta al status de la persona, a su capacidad de obrar, a las leyes relativas a la familia, a los derechos hereditarios.

La auténtica naturaleza jurídica de la nacionalidad como estado civil de la persona hace que la adquisición por residencia de la misma no puede confundirse con la que se lleva a cabo por carta de naturaleza, así lo han dichos los tribunales, pues mientras ésta constituye un genuino derecho de gracia, en que el requisito de la solicitud tiene el significado de ocasión o motivo pero no causa jurídica de la misma, la adquisición por residencia no puede concederse o denegarse sino cuando concurran las circunstancias legalmente previstas, de manera que no se trata de una concesión "stricto sensu" sino de un reconocimiento por concurrir al efecto los requisitos exigibles, advierte la jurisprudencia en Sentencia del Tribunal Supremo de 4 julio 2012 (RJ $\backslash 2012 \backslash 7703$ ), en igual sentido lo ha ratificado Sentencia del Tribunal Supremo de 5 de octubre de 2002 (RJ/2002/8873) y desarrollado la Sentencia de 22 de diciembre de 2003 (RJ/ 2004 /764), cuando refiere específicamente que a diferencia de la adquisición de nacionalidad por carta de naturaleza, donde han de concurrir circunstancias excepcionales (art. 21. 1 CC), cuando el extranjero solicita nacionalidad por residencia, es reglado el comportamiento, y ha de ser respetado, porque esta adquisición les convierte en ciudadanos españoles lo cual supone una serie de derechos refrendados en el artículo 23 de la Constitución española, de participación política, en conexión con los principios de soberanía del pueblo y el pluralismo político.

\section{c) La llamada discrecionalidad de la Administración en relación a los conceptos jurídicos indeterminados en sede de nacionalidad}

Los requisitos para obtener la nacionalidad española que regula el Código Civil en su artículo 22.4 son conceptos jurídicos indeterminados, ello hace importante la apreciación que tienen los tribunales sobre la actuación de la Administración en la valoración de los mismos.

La existencia de conceptos jurídicos indeterminados no faculta en modo alguno a la Administración para obrar con discrecionalidad, porque la inclusión de un concepto de esta naturaleza, no significa que se le haya otorgado capacidad a ésta para decidir con libertad y renunciar a la solución justa del caso, sino que viene obligada a la única decisión correcta a la vista de los hechos acreditados, añadiendo que el reconocimiento de la nacionalidad española no es una potestad discrecional sino un deber cuando concurren los requisitos legalmente previstos, tal como lo aborda la Sentencia del TS de 4 julio 2012, (RJ 2012 \7703).

En cuestiones de nacionalidad queda excluida la discrecionalidad de la Administración, la valoración de la misma lleva a una única solución justa, jurisdiccionalmente controlable, que se adopta por la propia Administración, a tenor de lo previsto en el art.103 CE, sin que se puedan ofrecer determinadas alternativas, que son propias de la llamada discrecionalidad 
administrativa, por tanto si una persona determinada cumple con los requisitos legales ha de concedérsele la nacionalidad, en este punto no cabe libertad de la administración(Cobas, 2013:12).

La jurisprudencia ratifica esto reiteradamente, así en la Sentencia del Tribunal Supremo de 5 de octubre 2002 (RJ/2002/8873), consideró improcedente la denegación de la nacionalidad destacando además, que la concesión de la nacionalidad no está sujeta a la discrecionalidad de la administración al decir en su Fundamento Derecho en referencia a la conducta cívica, que es uno de los requisitos exigidos para obtener la nacionalidad, por lo que la Administración no está habilitada para que actúe ya no con arbitrariedad, sino ni siquiera con discrecionalidad, puesto que este último concepto significa la posibilidad de elegir, entre varias soluciones, aquella que considere más conveniente.

Por ello, en relación a algunos de los requisitos necesarios para acceder a la nacionalidad, han ratificado concretamente los tribunales este tesis, que comparto, así al referirse a la buena conducta cívica, ha expresado la STS Sala de lo Contencioso-Administrativo, Sección 3era), de 3 de diciembre 2002, en su Fundamento de Derecho Tercero, que la naturaleza de concepto jurídico indeterminado no habilita a la Administración para actuar con discrecionalidad, ya que ha de“ optar, al decidir, por la única solución justa”. Insistiendo en que el concepto de la buena conducta cívica ha de ponerse en relación con su proyección en el ámbito constitucional sobre comportamientos de ausencia de vulneración del ordenamiento jurídico, especialmente en relación con el ejercicio de los derechos y el cumplimiento de los deberes prevenidos en el Título I de la Constitución (artículos 14 al 52).

En lo que respecta al orden público y el interés nacional que forman parte de los conceptos jurídicos indeterminados, empleados por la Administración para denegar la nacionalidad, también son excluidos de la discrecionalidad de la Administración igualmente, en correspondencia con lo que sostiene consolidada doctrina jurisprudencial. Vid. Sentencia del Tribunal Supremo de 22 de junio de 1982 (RJ 1982/4829), de 13 de julio de 1984 (RJ 1984/4673), de 24 de abril de 1993 (RJ 1993, 2766), de 14 de abril de 1998 (RJ 1998/3825), entra otras.

La idea central que sostienen estas sentencias y que destaca la STS 12 septiembre 2011 (RJ 2011/6931) es que la inclusión de un concepto indeterminado en la norma a aplicar no significa, sin más, que se haya otorgado capacidad a la Administración para decidir con libertad y renunciar a la solución justa del caso, sino que viene obligada a la única decisión correcta a la vista de los hechos acreditados. El reconocimiento de la nacionalidad española por residencia no es una potestad discrecional sino un deber cuando concurren los requisitos legalmente previstos, salvo que por fundadas razones de orden público o interés nacional proceda denegarla, para lo cual la Administración ha de expresar los hechos en los que se basa la denegación a fin de que la Jurisdicción pueda comprobar si efectivamente aquéllos afectan al orden público o al interés nacional, y a lo que añadiría, tampoco puede sujetarse el contenido de los requisitos, y su alcance a los avatares o decisiones de cada Registro del país, no es consecuente con una política estable ni con la seguridad jurídica, que en unos se hagan exámenes para ver los conocimientos de cultura y política españolas y en otros baste con la presentación de los documentos y la entrevista que hace la policía.

\section{REQUISITOS PARA LA OBTENCIÓN DE LA NACIONALIDAD ESPAÑOLA}

El artículo 22 del Código Civil sujeta la concesión de la nacionalidad española por residencia a dos tipos de requisitos: unos de carácter definido como son la formulación de la 
correspondiente solicitud y la residencia legal, continuada e inmediatamente anterior a la petición durante los plazos de diez, cinco, dos o un año, que según los casos se establece; y otros configurados como conceptos jurídicos indeterminados, bien de carácter positivo como es el caso de la justificación de buena conducta cívica y el suficiente grado de integración en la sociedad española, o bien de carácter negativo como es el caso de los motivos de orden público o interés nacional que pueden justificar su denegación. Es parca y general la regulación del legislador del Código Civil español, cuyo desarrollo se ha hecho a golpe de jurisprudencia, resoluciones e instrucciones dictadas por la Dirección General de los Registros y del Notariado (Cobas, 2013:12).

Los requisitos para obtener la nacionalidad responden a un estándar medio de conducta de la persona, capaz de ser asumido por cualquier individuo y cultura, en definitiva por un hombre medio y común, tal como acertadamente señala la jurisprudencia española en Sentencia del Tribunal Supremo de 12 de noviembre de 2002, Sala de lo ContenciosoAdministrativo ( RJ/2003/955).

\section{a) Los plazos y la permanencia en el país de forma regular y continuada}

El tiempo de permanencia en el país marcado por plazos constituye desde mi punto de vista el primero de los requisitos y el que marca el destino de los demás en la consecución de la nacionalidad, si no se tiene el tiempo de residencia, que ha se ser legal, continuada e inmediata a la solicitud, establecido por los artículos 22.1 y 22.3 del Código Civil español, no se puede optar por la nacionalidad.

El propio Código Civil delimita los plazos, dependiendo del lugar de nacimiento del extranjero y la existencia de Convenios con los países, de dos a diez años fija la ley el tiempo que ha de estar residiendo en España de forma legal y continuada, con lo cual ya establece un primer trato diferenciado entre los extranjeros, no es lo mismo a efectos de extranjería ser cubano, que ser africano o chino, para unos el tiempo es más reducido y para otros es extenso. Esto por supuesto se debe a razones históricas vinculadas con la colonización española en América Latina.

Las categorías de forma legal, continuada e inmediata, presupone que estando en situación irregular el extranjero, ese tiempo no cuenta a efectos de poder acceder a la nacionalidad, se requiere un status jurídico de legal, en cuanto a que la permanencia sea continuada, lo explica claramente la jurisprudencia cuando señala que: "el requisito de la continuidad en la residencia o presencia física no deja de considerarse existente por el hecho de que el interesado haya tenido que realizar, durante el período de tiempo contemplado, cortos y esporádicos viajes o salidas al extranjero, tal permisión, a falta de fijación «ex lege» de un límite a la duración y frecuencia de los mismos, no puede por menos de merecer una interpretación y aplicación restrictiva, que ha de ser ponderada bajo las perspectivas de la accidentalidad o no frecuencia en su realización, de la brevedad en su duración y de la justificación en sus motivos, pues mantener un criterio amplio y permisivo en esta materia, además de ser contrario a la «ratio legis» del precepto regulador de esta forma de adquisición de la nacionalidad, que, como prueba del ánimo del interesado de integrarse en la comunidad española, exige expresamente que su residencia sea continuada, lo que es sinónimo de no interrumpida, podría suponer la apertura de un peligroso y siempre recusable portillo al fraude de ley". Vid Sentencia del Tribunal Supremo, Sala de lo Civil de 19 septiembre 1988 $(\mathrm{RJ} \backslash 1988 \backslash 6838)$. 


\section{b) La integración}

Otro de los requisitos que exige el Código Civil para conceder la nacionalidad es "el suficiente grado de integración", a tenor de lo que señala el artículo 22. 4, que constituye un requisito bastante difícil no sólo de tener, sino también de demostrar por la persona que pretende obtener la nacionalidad y de indefinidos contornos jurídicos. Es un requisito complejo, reseñado sobre el lineamiento fundamental de la aceptación y seguimiento por parte del extranjero de los principios sociales básicos de la sociedad española, en especial aquellos que han sido recogidos en disposiciones legales, traducido y condensado todo esto, en la integración real y efectiva en las costumbres y forma de vida del pueblo español (Cobas, 2013:12).

En este sentido coincido con Ortega Giménez (2013:2), que asimila esta situación a la del arraigo en la sociedad en que vive una persona, lo cual se desprende de la propia regulación del Código Civil, que no se contenta con los plazos establecidos para conceder la nacionalidad, sino que también exige para los supuestos de nacionalidad por residencia la integración con el país, y con la sociedad, porque la nacionalidad genera un vínculo político, jurídico y social con el Estado, y ello requiere que este vínculo abarque la permanencia en la tierra y la integración a la misma, a las costumbres del país, a la cultura y a un estilo de vida determinado, o el idioma, que constituye una de la barreras que hay que vencer para poder acceder a la nacionalidad española, o en general a cualquier nacionalidad que se pretenda, porque el lenguaje es el primer vehículo de comunicación entre las personas.

Las soluciones en relacionan a los requisitos, se abordan casuísticamente, así en sentencia del TS de 12 de mayo de 2005, Sala de lo Contencioso-Administrativo, Sección 6ta, (RJ 2005\4226), se ha entendido vulnerado el principio de igualdad y se ha estimado el recurso, entendiendo que el recurrente está integrado en la sociedad española, lo que se deduce de su convivencia familiar, mujer e hijos españoles, encontrándose en fase de aprendizaje de la escritura del idioma español, aunque la doctrina predominante es la del dominio del idioma español, y porque ante la situación de dos personas casadas con españoles, que ambos hablan y entienden el idioma español, aun cuando ninguno de los dos lo escribe, de tal circunstancia de no escribir el idioma pese a hablarlo, el Tribunal «a quo» en un supuesto considera que es suficiente para apreciar integración en la sociedad española y en el caso del recurrente, por el contrario, lo niega lo que sin ninguna duda supone que en la Sentencia de 18 de septiembre de 2001 se ha apartado, sin justificación, del criterio que anteriormente había mantenido.

Resulta interesante la TS (Sala de lo Contencioso-Administrativo, Sección 6 ${ }^{\text {a }}$ ) de 12 diciembre 2011 (RJ $\backslash 2012 \backslash 2681$ ), en la que se deniega por la Dirección General de Registros y el Notariado, la solicitud a un ciudadano marroquí porque no ha justificado suficiente grado de integración en la sociedad española "ya que según informe de la Dirección General de la Policía entiende y se expresa con dificultad en la lengua castellana, estando arraigado a las costumbres de su país de origen y porque fue un destacado miembro del colectivo musulmán que lideró Gabino", en contraste el magistrado ponente consideró procedente concederle la nacionalidad española porque entendió que el recurrente lleva residiendo de forma real y efectiva e ininterrumpida desde el 23 de enero de 1988, que ha servido en el ejército español, ha llegado a disponer del DNI español y llegó a ejercer su voto en las elecciones generales de 1982 y en el referéndum nacional de la OTAN con su tarjeta de identidad al constar inscrito en el censo. Por otra parte el Encargado del Registro en comparecencia concluyó que habla el idioma castellano, incluso en expresiones coloquiales y se encuentra integrado en las costumbres españolas.

Sin embargo en otros casos los tribunales han denegado la nacionalidad por la carencia de acreditación en relación al idioma español, porque entendió que el dominio lingüístico del 
solicitante era escaso, y aunque el solicitante adujo que padecía un problema de tartamudez, observó la STS (Sala de lo Contencioso-Administrativo, Sección6 ${ }^{a}$ ) Sentencia de 3 noviembre 2009. RJ 2010 \1251 que tras veinte años de residencia en España no constituye una excusa para el defectuoso conocimiento de la lengua española.

De todas formas, el tema es espinoso. Resulta altamente complicado para un extranjero cumplir todos y cada uno de los requerimientos o parámetros que pueden indicar una integración, media, si no ya total a España, sobre todo por las dificultades actuales económicas que vive la sociedad española, que afectan por demás a los extranjeros mucho más que a los españoles. Por razones obvias, y que dificultan material, logísticamente, así como en el ámbito probatorio alcanzar la real integración en la sociedad española.

La política española no ha permanecido inerte ante esto, se han producido algunas iniciativas, con mayor o menor éxito para favorecer la integración de los inmigrantes, aunque me muestro algo escéptica con la virtualidad de estas medidas. Así se ha sopesado y trabajado en la integración con algunas iniciativas que sólo menciono a manera de ejemplo, como las Escuelas de Acogida; iniciativa legislativa de la Comunidad Valenciana, a tenor de la Ley 15/2008, de 5 de diciembre, de la Generalitat, de Integración de las Personas Inmigrantes en la Comunidad y el Decreto 93/2009, de 10 de julio, del Consell, por el que se aprueba el Reglamento de la Ley 15/2008, de 5 de diciembre, de la Generalitat, de Integración de las Personas Inmigrantes en la Comunidad Valenciana, que trazó las bases para un modelo con vistas a integrar a los inmigrantes, también otras Comunidades han trazado iniciativas en igual sentido como Cataluña (Monereo y Triguero, 2010:11-13).

Otras ideas en relación a ello ha sido el contrato de integración, que en España no ha tenido demasiada fuerza y al decir de algún autor ha sido uno de los pilares más débiles de la autodenominada política de inmigración (Solanes, 2009:60).

La idea de los contratos de integración bien podía llamarse de otro modo; habida cuenta que un contrato está fundamentado sobre el acuerdo de voluntades, y que en el caso de esta modalidad contractual, no está presente, porque como señala algún sector de la doctrina, que comparto, estamos en presencia de un acuerdo en el que las partes se encuentran en una clara situación de desigualdad, de tal forma que el contrato es prácticamente de adhesión, sin que el inmigrante pueda decir nada al respecto, además se le exige en el momento inicial que es el de mayor debilidad jurídica. No se tienen en cuenta, por tanto, ni las diferentes necesidades ni las distintas situaciones en el momento de la llegada, por ejemplo, una muy elemental como que el extranjero no pueda asumir su coste económico en los casos en los que la legislación estipula que a él le corresponde (Solanes, 2009:67-68).

En lo que concierne al contrato de integración, aunque parece un esfuerzo muy loable por parte de algunas Comunidades Autonómicas, y que está en consonancia con las medidas de integración adoptada por Europa (Nuñez, 2012:85), es inoperante, porque la verdadera integración se obtiene con un empleo, sólo el acceso al mercado laboral permite a las personas tener dignidad, y poder sentirse parte de un país, de un proceso y de una sociedad y es cuando comienza la verdadera integración, y comienzan a interesarse y a conocer mejor el entorno, por eso y, aun cuando puede existir la autorización para residir sin la de trabajo, generalmente vienen aparejadas. Este constituye un primer punto de partida y el más importante, aunque en estos momentos de crisis económica ha desaparecido el trabajo, no sólo para los extranjeros sino para los nacionales; realidad que no podemos desdeñar. 


\section{c) Buena conducta cívica}

La buena conducta constituye dentro de los requisitos para acceder la nacionalidad uno de los que más ha abordado la jurisprudencia, regulado en el CC en el artículo 22. 4 del CC español en las breves líneas que le dedica el legislador a ello y conjuntamente con los otros requisitos.

Una de las notas de color más distintivas al tema de la buena conducta cívica la ofrece la jurisprudencia en STS de 22 de diciembre de 2003 (RJ 2004 /764), cuando la vincula con la interpretación de las normas, y advierte que la buena conducta cívica, ha de ser apreciada e interpretada sobre la base del art 3 del CC, porque para abordar la solución del problema que se presentaba, el concepto jurídico indeterminado que emplea el artículo 22. 4 del CC ha de ponerse en relación con lo que preceptúa el citado artículo 3.1 que establece que la norma ha de interpretarse teniendo en cuenta "la realidad social del tiempo en que la norma ha de aplicarse". De ahí que el Tribunal entendió con sobrada razón, que una persona implicada en tráfico de drogas, que constituye una pandemia de la sociedad española en estos momentos, no debe ser destinatario de la nacionalidad española.

A contrario sensu, ello no significa en modo alguno que exista una rigidez en el tratamiento de la conducta de las personas en sede de nacionalidad, por parte de la jurisprudencia. Cada caso es tratado en particular, y no automáticamente, por ello en un supuesto en que un ciudadano de nacionalidad vietnamita y asilado en España solicitó la adquisición de la nacionalidad española, frente a la desestimación por parte del Ministerio de Justicia de 29 de enero de 2005, por no considerar debidamente acreditada la buena conducta cívica, el TS se desmarca de la citada Resolución, y de la posición del Abogado del Estado y declara no haber lugar el recurso de casación, al entender, en primer orden de cosas que aunque es verdad que haber sido condenado en sede penal, aun cuando sea por una falta, tiene relevancia para valorar la «buena conducta cívica» de quien solicita adquirir la nacionalidad española por residencia, ello no significa que toda sentencia penal condenatoria traiga automáticamente consigo un estigma de "mala conducta cívica" a efectos del artículo 22 del Código Civil (SSTS de 5 de octubre de 2002 y de 3 de noviembre de 2004, entre otras). Incluso tratándose de hechos ilícitos más graves que el cometido en su día por el solicitante, la existencia de una previa condena penal es un elemento que debe ser valorado de acuerdo con las circunstancias del caso, pues no todos los delitos y faltas ponen de manifiesto una idéntica ausencia de civismo. En segundo lugar a la hora de hacer las valoraciones del civismo de quien solicita la adquisición de la nacionalidad española por residencia, también deben ponderarse cualesquiera otros datos positivos o negativos que, al margen de lo penal, puedan poner de manifiesto cuál es la actitud del solicitante en la sociedad.

Por ello coincido con Ortega (2011:2), cuando señala que la posición del Tribunal Supremo es clara, y que nada tiene que ver el concepto de buena conducta cívica con la carencia de antecedentes penales, ya que la misma constituye un requisito adicional sobre la mera observancia de una conducta de no trasgresión de las normas penales o administrativas sancionadoras, impuesto por el ordenamiento jurídico en razón del carácter excepcional que supone el reconocimiento de la nacionalidad por residencia y, por ende, envuelve aspectos que trascienden los de orden penal y ha de ser valorada atendiendo a la conducta del solicitante durante un largo periodo de tiempo de permanencia en España, por lo que entiende el autor, que no puede identificarse sin más con la ausencia de antecedentes penales o policiales. Así en Sentencia de la Audiencia Nacional, de 19 de julio de 2004, Sala de lo Contencioso Administrativo (JUR 2006\266082), a pesar de la existencia de un expediente penal abierto, pero en el que no se hubiera tomado ninguna medida con el recurrente, el 
juzgados consideró otras circunstancias familiares, de trabajo y tiempo de residencia como elementos suficientes para hacerle acreedor de la nacionalidad española.

Resulta significativa la STS (Sala de lo Contencioso-Administrativo, Sección $6^{\text {a }}$ ) Sentencia de 14 noviembre 2011 (RJ $2012 \backslash 2185$ ), donde se delimita el concepto de civismo, que consiste solo en no delinquir, sino en respetar unas pautas mínimas de respeto y solidaridad con respecto al resto de la sociedad, por lo cual entendió que circular con un automóvil sin seguro obligatorio: conducta contraria a Derecho que merece un evidente juicio de desvalor, con independencia de que finalmente no recayera condena penal por dichos hechos en virtud de la prescripción de las actuaciones, encontrando procedente la denegación de la nacionalidad. Y aun más esclarecedora lo es la Sentencia del Tribunal Supremo, de 16 de marzo de 1999 ( RJ 1999\3044 Sala de lo Contencioso-Administrativo, Sección6 6 ), al apreciar como determinantes de la falta de buena conducta "determinados comportamientos que no pueden admitirse como propios de la misma" sin otro fundamento objetivo formalmente justificado que unos antecedentes policiales cancelados y una supuesta resolución de expulsión que se dice basada en ellos parece difícil sin aceptar un concepto de buena conducta cívica en un sentido extensivo, dudosamente constitucional -como "el comportamiento global del individuo, incluso en sus relaciones privadas, enjuiciable desde una perspectiva metajurídica, de acuerdo con los valores morales arraigados o con las pautas de conducta, sea de la colectividad en su conjunto, sea de grupos sociales más restringidos"-, y no en el único justificable constitucionalmente, como la ausencia del "incumplimiento de deberes jurídicos explícitos de trascendencia pública, genéricamente descritos como deber de observancia de buena conducta, cuando así lo exija razonablemente el interés público que con ello pretende protegerse", Vid. Sentencia del Tribunal Constitucional 114/1987, (RTC 1987/114).

La valoración de una conducta cívica como buena, así como el grado de integración en la sociedad española como suficiente, quedan en manos del juzgador, que deberá tener particularmente en cuenta hechos y comportamientos que, al margen de posibles antecedentes penales, permitan concluir la existencia o no de una «buena conducta cívica», concepto jurídico indeterminado que debe fijarse a partir de datos fundamentalmente personales que, como tales, deberán ser ponderados por el juez. Por tanto habrá que valorar no sólo los comportamientos negativos que tienen los solicitantes de la nacionalidad, sino aspectos positivos en su actuación, que se toman como "elementos inequívocamente definidores de la buena conducta del recurrente, como podrían ser que el recurrente hubiera participado en actividades o trabajos en beneficio de la comunidad, que contara con certificados de buena conducta de autoridades o entidades públicas o privadas, o que hubiesen avalado su buena conducta personas próximas a su entorno a través de una eventual prueba testifical, como apunta Rubio Torrano (2010:3) siguiendo la doctrina de la jurisprudencia.

\section{CONCLUYENDO SOBRE EL TEMA}

Al finalizar este trabajo es posible aventurar algunas conclusiones, que por supuesto no cierran el debate sobre el tema, pero que pueden llevar tanto a trabajos futuros como a reflexionar sobre este tema, tan social y político a la vez.

En primer orden de cosas hay que señalar que la obtención de la nacionalidad no constituye un camino de rosas para los extranjeros que pretenden alcanzarla, más bien, es un 
camino extenso, largo y complejo, ya no sólo de trámites administrativos, sino de indefiniciones en cuanto al contenido de los requisitos, que abarcan, cuáles son los límites, lo que trae causa en la regulación del Código Civil español en la materia, que es parca y general. A lo que une que los requisitos de integración y buena conducta cívica son conceptos jurídicos indeterminados, que se han ido construyendo a fuerza de la jurisprudencia y alguna norma que los ha ido matizando, lo que no mejora para nada el tratamiento del tema. Ahora bien, esta indeterminación por parte del legislador del contenido de los requisitos de la nacionalidad (excluido los plazos que si están determinados), no abre el camino a decisiones discrecionales de la Administración, por esta razón su otorgamiento no es libre y no depende de las decisiones subjetivas de ésta. Si se cumplen los requisitos, ha de concederse.

En lo referido a los requisitos para obtener la nacionalidad española por residencia y trabajo, y en general para materia de nacionalidad parece otearse en el horizonte importantes cambios. Por lo menos a efectos de recientes noticias que invaden el panorama jurídico.

Dos de importancia destacan dentro de las novedades que parecen incidir en una cercana reforma sustancial a las cuestiones de la concesión de la nacionalidad. En primer orden de cosas, aunque ya lleva algún tiempo puesta en el tapete de negociaciones y conversaciones en la materia, se plantea la introducción de criterios objetivos en las pruebas de integración necesarias para demostrar que se está integrado a la sociedad española. Aquí cabe apuntar, que lo primero que habrá que establecerse son los criterios objetivos en relación a la demostración y acreditación de la integración, habida cuenta que cada Registro Civil lo hace según su leal saber y entender. Para algunos funcionarios basta con la acreditación de la documentación, y la previa entrevista por la policía, y en otros Registros Civiles se examina al solicitante. La falta de homogeneidad y sistematización, evidentemente no favorece el acceso a la nacionalidad, genera inseguridad jurídica, y vulnera el principio de igualdad de todos ante la ley.

El órgano encargado de conceder la nacionalidad que ha sido histórica y legislativamente el Registro Civil, entendiendo que la nacionalidad afecta el estado civil de las personas, también ha sufrido reformas. Situación que ha comenzado a vaticinarse desde que se incorporaron a los Registradores de la Propiedad y Notarios en la tramitación de la nacionalidad por los encargos o encomiendas del Ministro de Justicia a los citados cuerpos. Recientemente se ha aprobado el Real Decreto-ley 8/2014, de 4 de julio, de aprobación de medidas urgentes para el crecimiento, la competitividad y la eficiencia (BOE núm. 163, de 5 de julio de 2014), que en su Disposición adicional decimonovena, prorroga la entrada en vigor de la Ley 20/2011, de 21 de julio del Registro Civil, en la parte que al día de la publicación de este Real Decreto-ley no hubiera entrado en vigor, lo se producirá el día 15 de julio de 2015, y a efectos de este trabajo, el Registro Civil estará encomendado a los Registradores de la Propiedad y Mercantiles, y con ello las cuestiones relacionadas con la nacionalidad.

En cualquier caso, el tiempo dirá, pero con independencia a todas estas reformas, la real integración de un extranjero a una sociedad pasa por contar con un empleo, el acceso al trabajo, sigue siendo desde mi punto de vista, la vía real y efectiva para que alguien comience a sentirse parte de una sociedad y una de las claves fundamentales para que estos se integren en la sociedad y comiencen a tejer un conjunto de redes sociales (Monereo y Triguero, 2010: 77). Todo lo demás efectivamente son reformas que coadyuvarán a la agilidad y uniformidad en la tramitación, que se agradece, para quien haya logrado una estabilidad económica en el país. 


\section{BIBLIOGRAFÍA}

COBAS COBIELLA, M. E. (2013). "Nacionalidad y Registradores de la Propiedad. Una curiosa combinación”. En Diario La Ley, Año XXXIV, no 8050, 25 marzo 2013, Madrid: La Ley, pp. 2-15.

MONEREO PÉREZ, J. L. y TRIGUERO MARTÍNEZ, L. A. (2010). "El Modelo de protección legal del trabajador extranjero tras la reforma realizada por la Ley Orgánica 2/ 2009, de 11 de diciembre. En Revista Doctrinal Aranzadi Social, 19: 77.

NUÑEZ SÁNCHEZ, E.M. (2012). "Comunidad Valenciana: Una integración de vanguardia. La Escuela de acogida". En Barataria. Revista Castellano-Manchega de Ciencias Sociales, 13: 85.

NAVARRO GÓMEZ- FERRER, S.; LLOPIS RAUS A, F.; ORTEGA GIMENEZ, A. y COBAS COBIELLA, M. E. (2013). "Adquisición de la nacionalidad española por residencia: la encomienda de nacionalidad a los Registradores de la Propiedad". En Diario La Ley, Año XXXIV, nº 8206, 9 al 15 de diciembre 2013, Madrid: La Ley, pp 8-17.

ORTEGA GIMENEZ, A. y HERRERO BOTELLA, J. M. (2013). "Valoración de la integración del extranjero en la sociedad española, cuando solicita la nacionalidad española por residencia: visión actual y futura en España y en parte del extranjero". En Revista Aranzadi Doctrinal, nº 8/2013, parte Estudio. Pamplona: Aranzadi, p. 8.

ORTEGA GIMÉNEZ, A. (2011). "Antecedentes penales y acceso a la nacionalidad española". En Actualidad Jurídica Aranzadi, no 812/2011 parte Comentario Editorial Pamplona: Aranzadi. p. 1.

ORTEGA GIMÉNEZ, A, ALARCÓN MORENO, J, ALONSO GARCÍA, E. "Las Escuelas de Acogida: un nuevo modelo de integración de los inmigrantes en la comunidad valenciana" (2012). En Revista de Sociales y Jurídicas, $n^{\circ}$ 8, Elche: Universidad Miguel Hernández, p. 283.

RUBIO TORRANO, E. (2010). "Adquisición de nacionalidad por residencia y exigencia de buena conducta cívica". En Aranzadi Civil, Pamplona: 3: 11-14.

SOLANES CORELLA, A. (2009). "integrando por ley de los contratos europeos de integración al compromiso de la Ley autonómica valenciana". En Revista de Derecho Migratorio y extranjería. Madrid: Thomson Reuters, 200: 47-75. 


\section{Breve currículo:}

\section{María Elena Cobas Cobiella}

Profesor Contratado Doctor de la Universidad de Valencia, España. Licenciada en Derecho por la Universidad de la Habana en 1983. Profesora de la Facultad de Derecho, Departamento Civil, Universidad de la Habana, Cuba (1983-1999).Catedrática de Derecho Civil, Facultad de Derecho, Universidad de la Habana, Cuba (1996). Notario Público en Cuba (1992-1998). Catedrática de la Escuela de Salud Pública del Ministerio de Salud Pública de Cuba en el área de Master y Postgrados (999-2000). Doctora en Derecho Civil por la Universidad de Valencia. España (2001). 